\title{
PERSEPSI STAKEHOLDER TERHADAP PENGEMBANGAN BADAN USAHA MILIK DESA (BUMDES) DI SUNGAI LANGKA, KECAMATAN GEDONG TATAAN KABUPATEN PESAWARAN
}

\author{
STAKEHOLDERS PERCEPTION OF DEVELOPMENT \\ VILLAGE OWNED ENTERPRISES (BUMDES) IN SUNGAI LANGKA, \\ GEDONG TATAAN SUB DISTRICT, PESAWARAN DISTRICT
}

\author{
Tri Pujiana*, Dwi Arianti, Abdul Mutolib \\ Magister Penyuluhan dan Komunikasi Pertanian, Fakultas Pertanian, \\ Universitas Lampung Bandar Lampung 35141 \\ *Email: tripujiana.unila@gmail.com \\ (Diterima 20-02-2019: Disetujui 15 Juli 2019)
}

\begin{abstract}
ABSTRAK
Penelitian ini bertujuan untuk menganalisis persepsi stakeholder terhadap pengembangan Badan Usaha Milik Desa (Bumdes) Ramaksa di Sungai Langka. Penelitian ini bersifat deskriptif dengan pengumpulan data dilakukan secara kualitatif menggunakan pedoman wawancara mendalam kemudian dianalisis isi (content analysis). Penelitian dilakukan di Bumdes Ramaksa Desa Sungai Langka Kecamatan Gedong Tataan Kabupaten Pesawaran. Teknik penentuan informan menggunakan teknik purposive sampling. Subjek penelitian adalah stakeholder program Bumdes yaitu Kepala Desa Sungai Langka, dua orang pelaksana operasional Bumdes dan dua orang masyarakat Desa Sungai Langka. Penelitian ini dilaksanakan pada bulan November 2018. Fokus penelitian ini adalah keberadaan Bumdes, kontribusi Bumdes dalam penguatan ekonomi dan pembangunan desa serta persepsi stakeholder terhadap perkembangan Bumdes Ramaksa Desa Sungai Langka. Hasil penelitian menunjukkan bahwa unit usaha yang dijalankan oleh Bumdes Ramaksa antara lain unit usaha pengelolaan isi ulang air minum, lembaga keuangan mikro, peternakan, dan sub agen air minum Izaura. Pemilihan unit usaha ini didasarkan pada sumber daya dan potensi yang ada di Desa Sungai Langka. Badan usaha milik desa Ramaksa dibentuk berdasarkan asas manfaat dan peningkatan kesejahteraan masyarakat desa. Persepsi stakeholder terhadap pengembangan Bumdes Ramaksa dilihat dari empat aspek, yaitu aspek ekonomi, ekologi, sosial dan kelembagaan. Dari keempat aspek yang dinilai, Bumdes Ramaksa sudah tergolong baik. Menurut informan, program Bumdes sebagai inplementasi program pemberdayaan masyarakat berupaya untuk menciptakan pertumbuhan di bidang ekonomi rakyat dan pemerataan kesejahteraan melalui perluasan kesempatan berusaha bagi usaha kecil masyarakat yang diukur dari peningkatan pendapatannya.
\end{abstract}

Kata kunci: Bumdes, persepsi, stakeholder

\begin{abstract}
This study aims to analyze stakeholder perceptions of the development of the Ramaksa VillageOwned Enterprises (Bumdes) on the Sungai Langka. This research is descriptive with data collection done qualitatively using in-depth interview guidelines then analyzed content (content analysis). The study was conducted at the Bumdes Ramaksa in Sungai Langka Village, Gedong Tataan Subdistrict, Pesawaran District. The technique of determining informants used purposive sampling technique. The research subjects were stakeholders, namely the Head of the Sungai Langka, operational implementers and two people from Sungai Langka. The research was conducted in November 2018. The focus of this research was the existence of Bumdes, the contribution of the Bumdes in strengthening the economy and village development as well as stakeholder perceptions of the development of the Bumdes Ramaksa in the Sungai Langka. The results showed that the business units run by the Bumdes Ramaksa included drinking water refill management business units, microfinance institutions, livestock, and Izaura drinking water subagents. The selection of this business unit is based on the resources and potential in the Sungai
\end{abstract}




\section{PERSEPSI STAKEHOLDER TERHADAP PENGEMBANGAN BADAN USAHA MILIK DESA (BUMDES) DI SUNGAI LANGKA, KECAMATAN GEDONG TATAAN KABUPATEN PESAWARAN \\ Tri Pujiana, Dwi Arianti, Abdul Mutolib}

Langka. The business entity owned by the village of Ramaksa was formed based on the principle of benefits and improving the welfare of the village community. Stakeholder perceptions of the development of the Bumdes Ramaksa are viewed from four aspects, namely economic, ecological, social and institutional aspects. Of the four aspects assessed, the Bumdes Ramaksa has been classified as good. According to the informant, the Bumdes program as an implementation of the community empowerment program seeks to create growth in the field of people's economy and equitable welfare through the expansion of business opportunities for small-scale business people as measured by increased income.

Keywords: Bumdes, perceptions, stakeholders

\section{PENDAHULUAN}

Kementerian Negara Pembangunan Daerah Tertinggal (KPDT) melakukan perubahan paradigma pembangunan daerah tertinggal yang sebelumnya berbasis pada kawasan menjadi berbasis pedesaan. Pembangunan pedesaan dilihat sebagai upaya mempercepat pembangunan pedesaan melalui penyediaan sarana dan prasarana (Amanda, 2015). Salah satu upaya tersebut adalah dengan membentuk Badan Usaha Milik Desa (Bumdes). Bumdes menurut Ridlwan (2014) merupakan suatu lembaga perekonomian desa yang memiliki peranan penting dalam mewujudkan kesejahteraan masyarakat, desa, dan pemerintah.

Definisi Bumdes dalam UU No. 6 tahun 2014 yaitu badan usaha yang seluruh atau sebagian besar modalnya dimiliki oleh desa melalui penyertaan secara langsung yang berasal dari kekayaan desa yang dipisahkan guna mengelola aset, jasa pelayanan, dan usaha lainnya untuk kesejahteraan masyarakat. Tujuan dari pendirian Bumdes ini untuk meningkatkan pendapatan desa (Kurniawan, 2016). Setiap tahapan program Bumdes melibatkan masyarakat secara langsung supaya masyarakat mengerti akan masalah yang dihadapi serta dapat mengentaskan permasalahan mereka sendiri sampai mereka mandiri (Atmojo, 2015).

Salah satu kabupaten yang telah mendirikan Bumdes adalah Kabupaten Pesawaran yang diamanatkan dalam Peraturan Bupati No. 52 Tahun 2015 Tentang Pendirian Bumdes. Berdasarkan data dari Badan Pemberdayaan Masyarakat dan Pemberdayaan Desa (BPMPD) Provinsi Lampung tahun 2017, dari 144 desa yang ada di Kabupaten Pesawaran hanya terdapat delapan desa yang memiliki Bumdes. Salah satu Bumdes yang ada di Kabupaten Pesawaran adalah Bumdes Ramaksa yang berada di Desa Sungai Langka.

Peran pemerintah desa dalam pengelolaan kelembagaan merupakan unit terdepan pembangunan kepada masyarakat, terutama Bumdes merupakan 
program pemerintah yang harus diberdayakan. Peran pemerintah Desa dalam mengelola Bumdes yakni sebagai pembentukan dan pengembangan Bumdes, sebagai mediator pelatihan dan motivator terhadap terbentuknya pengurus dan organisasi Bumdes serta sebagai pengawasan (Chintary dan Lestari, 2016). Agar segala bentuk kebijakan bisa diterapkan diperlukan pemahaman terhadap persepsi stakeholder dalam pengambil keputusan terkait Bumdes tersebut.

Robbins dan Stephen (2003), menyatakan bahwa persepsi satu individu terhadap satu obyek sangat mungkin memiliki perbedaan dengan persepsi individu yang lain terhadap obyek yang sama. Menurutnya, hal ini disebabkan oleh beberapa faktor yang mempengaruhinya, yaitu karakteristik pribadi pelaku persepsi, target yang dipersepsikan, dan lingkungan atau situasi dimana persepsi itu dilakukan. Perbedaan persepsi stakeholder ini sangat dipengaruhi oleh latar belakang budaya dan dampak dari tujuan pengelolaan tersebut terhadap kondisi kehidupan (Alfiya et al, 2012). Perbedaan persepsi menghasilkan visi yang berbeda terhadap manajemen pada suatu area, dan seringkali memicu konflik.

Persepsi sangat dipengaruhi oleh latar belakang ekonomi, sosial, budaya, institusional dan juga tingkat kepentingan para pihak stakeholder (Alviya et al, 2012). Pemahaman terhadap persepsi tentang kehidupan organisasi mutlak diperlukan. Hal ini dikarenakan persepsi akan mempengaruhi perilaku anggota organisasi, dan perilaku anggota akan mempengaruhi motivasinya (Januraga et al, 2009). Berdasarkan hal tersebut, hasil analisis wawancara mendalam terhadap persepsi stakeholder terhadap pengembangan Bumdes Ramaksa di Sungai Langka, Kecamatan Gedong Tataan Kabupaten Pesawaran perlu dilakukan.

\section{BAHAN DAN METODE}

Penelitian ini bersifat deskriptif. Pengumpulan data dilakukan secara kualitatif dengan menggunakan pedoman wawancara mendalam kemudian dilakukan analisis isi (content analysis) untuk mengetahui persepsi stakeloders (pengambil kebijakan) terhadap Bumdes. Penelitian dilakukan di Bumdes Ramaksa Sungai Langka Kecamatan Gedong Tataan Kabupaten Pesawaran.

Teknik penentuan informan menggunakan tehnik purposive sampling untuk informan pokok. Subjek penelitian adalah stakeholder program Bumdes, yaitu Kepala Desa Sungai Langka, dua orang pelaksana operasional Bumdes Ramaksa. Informan tambahan terdiri atas 


\section{PERSEPSI STAKEHOLDER TERHADAP PENGEMBANGAN BADAN USAHA MILIK DESA (BUMDES) DI SUNGAI LANGKA, KECAMATAN GEDONG TATAAN KABUPATEN PESAWARAN \\ Tri Pujiana, Dwi Arianti, Abdul Mutolib}

dua orang penduduk Desa Sungai Langka yang menerima manfaat dari adanya Bumdes tersebut. Penelitian ini dilaksanakan pada bulan November 2018. Fokus penelitian ini adalah keberadaan Bumdes, kontribusi Bumdes dalam penguatan ekonomi dan pembangunan desa serta persepsi stakeholder terhadap perkembangan Bumdes Ramaksa Desa Sungai Langka.

Pengumpulan data primer dilakukan dengan observasi, depth interview, dan dokumentasi tehadap informan yang telah ditentukan. Data sekunder didapatkan dari literatur dan instansi terkait. Setelah data terkumpul kemudian dilakukan analisis menggunakan model interaktif menurut Miles dan Hubberman yang diterjemahkan oleh Husani dan Purnomo (2009). Analisis model interaktif melalui tiga tahap, yaitu reduksi data, penyajian data, dan penarikan kesimpulan atau verifikasi.

Proses reduksi yaitu memilih, memfokuskan, menyederhanakan dan mengabstraksi data dari berbagai sumber. Selanjutnya proses mempertegas, memperpendek, membuang yang tidak perlu, menentukan fokus, dan mengatur data sehingga kesimpulan bisa dibuat. Kedua, penyajian data dengan baik agar lebih mudah dipahami. Ketiga yaitu menarik kesimpulan yang dibuat setelah pengumpulan data (Sugiyono, 2001).

\section{HASIL DAN PEMBAHASAN}

\section{Karakteristik Informan}

Informan pada penelitian ini adalah tiga orang pengurus Bumdes yang terdiri atas penasehat Bumdes, direktur Bumdes (pengurus operasional) dan bendahara unit usaha keuangan mikro serta dua masyarakat Desa Sungai Langka sebagai penerima manfaat adanya Bumdes. Karakteristik responden dapat dilihat pada Tabel 1.

Tabel 1. Daftar informan

\begin{tabular}{cccc}
\hline No & Umur & $\begin{array}{c}\text { Pendidikan } \\
\text { terakhir }\end{array}$ & Jabatan \\
\hline 1. & 45 & S1 & Penasehat \\
2. & 39 & SMA & Ketua \\
3. & 41 & SMA & Bendahara unit \\
& & & usaha \\
4. & 38 & SMA & Warga \\
5. & 35 & SMA & Warga \\
\hline
\end{tabular}

Tabel 1 menunjukkan karakteristik informan berdasarkan umur, pendidikan terakhir dan jabatan informan di Bumdes Ramaksa. Seluruh informan telah menempuh pendidikan menengah ke atas. Hal ini menunjukkan bahwa pola pikir pengurus Bumdes lebih terbuka terhadap inovasiinovasi baru, seperti hadirnya badan usaha yang berada di bawah pemerintah desa dengan memanfaatkan sumber daya manusia dan sumber daya alam yang ada di desa. Seluruh pengurus Bumdes juga berada di usia yang produktif, hal ini menunjukkan bahwa usia mereka telah matang dalam merencanakan dan melaksanakan kegiatan, dan karena 
semakin tua umur seseorang maka akan semakin baik tingkat kreativitasnya dalam merencanakan program dan lebih mudah membangun komunikasi dengan sesama.

\section{Keberadaan dan Kontribusi Bumdes Ramaksa}

Pembentukan Bumdes di Sungai Langka berdasarkan Peraturan Desa Sungai Langka Nomor IV Tahun 2016 tentang Badan Usaha Milik Desa (BUM Des). Berpedoman pada Peraturan Menteri Desa Pembangunan Daerah Tertinggal dan Transmigrasi Republik Indonesia Nomor 4 Tahun 2015 tentang Pendirian, Pengurusan dan Pengelolaan, dan Pembubaran Badan Usaha Milik Desa. Pada awal berdirinya badan usaha milik desa ini, Bumdes mendapatkan dana hibah dari alokasi dana desa sebesar sepuluh persen atau kurang lebih $\mathrm{Rp}$ 80.000.000. Kemudian pemanfaatannya oleh Bumdes diolah menjadi modal awal usaha yang ada di Bumdes.

Usaha yang dijalankan oleh Bumdes Ramaksa sebanyak empat bidang usaha, antara lain unit usaha pengelolaan air isi ulang, unit usaha lembaga keuangan mikro, unit usaha peternakan, dan unit usaha sub agen air minum Izaura. Pemilihan unit usaha ini didasarkan pada sumber daya dan potensi yang ada di Desa Sungai Langka. Di desa ini terdapat mata air pegunungan yang dimanfaatkan untuk air minum isi ulang. Di Desa Sungai Langka juga sudah terbentuk delapan Kelompok Wanita Tani (KWT) yang masing-masing kelompok memiliki usaha di bidang kuliner dan kerajinan. Kelompok Wanita Tani tersebut diberi modal untuk pengelolaan usaha kemudian produk dari KWT ini dipasarkan oleh Bumdes ke luar desa.

Pada unit usaha peternakan, Bumdes memberikan modal berupa kambing etawa, sedangkan pada unit usaha sub agen air minum izaura diberikan modal untuk membeli air minum dari Pulau Jawa yang kemudian dipasarkan oleh Bumdes. Bumdes Ramaksa sudah berjalan selama satu tahun, namun ada unit usaha yang tidak berjalan sesuai dengan tujuan awal yaitu unit usaha sub agen air minum izaura.

Modal awal yang dimiliki oleh Bumdes ini sebenarnya tidak mencukupi untuk modal awal seluruh unit usaha, namun bisa diatasi dengan pemanfaatan fasilitas desa yang tidak terpakai sebagai tempat untuk membuka usaha air isi ulang. Selain dana hibah desa yang digunakan sebagai modal awal, pada ahun 2018 Bumdes ini juga mendapat dana dari APBDes sebesar kurang lebih Rp 41.000.000 dan dari dana program gadis (gerakan desa ikut sejahtera) dari 


\section{PERSEPSI STAKEHOLDER TERHADAP PENGEMBANGAN BADAN USAHA MILIK DESA (BUMDES) DI SUNGAI LANGKA, KECAMATAN GEDONG TATAAN KABUPATEN PESAWARAN \\ Tri Pujiana, Dwi Arianti, Abdul Mutolib}

pemerintah Kabupaten Pesawaran) sebesar Rp 100.000.000.

Bumdes Ramaksa dibentuk berdasarkan asas manfaat dan peningkatan kesejahteraan masyarakat desa. Hadirnya Bumdes mempermudah masyarakat dalam pemenuhan kebutuhan air minum yang dikonsumsi sehari-hari. Bumdes juga berusaha meningkatkan kesejahteraan masyarakat dengan penyertaan modal pada usahausaha yang dimiliki warga juga memberikan modal kambing yang dipelihara langsung oleh warga.

\section{Persepsi Stakeholder Pengembangan Bumdes}

Persepsi stakeholder terhadap pengembangan Bumdes Ramaksa di Desa Sungai Langka dinilai dari empat hal, yaitu aspek ekonomi, aspek ekologi, aspek sosial dan aspek kelembagaan. Secara keseluruhan persepsi stakeholder terhadap pengembangan Bumdes tergolong baik. Persepsi yang positif akan membentuk kesadaran pada pelakunya (Beding, 2015). Menurut informan, program Bumdes sebagai inplementasi program pemberdayaan masyarakat berupaya untuk menciptakan pertumbuhan di bidang ekonomi rakyat dan pemerataan kesejahteraan melalui perluasan kesempatan berusaha bagi usaha kecil masyarakat yang diukur dari peningkatan pendapatannya. Keberadaan Bumdes ini diharapkan mampu menggerakkan perekonomian masyarakat Desa Sungai Langka.

\section{a. Aspek Ekonomi}

Aspek ekonomi yang dinilai dari terbentuknya Bumdes adalah penyerapan tenaga kerja, peningkatan pendapatan, nilai guna fasilitas, dan akses pasar. Bumdes Ramaksa yang dibentuk pada tahun 2017 memberikan kesempatan kerja kepada warga yang belum memiliki perkerjaan. Kehadiran Bumdes Ramaksa menyerap tenaga kerja yang cukup banyak baik dari segi pengelola Bumdes itu sendiri ataupun sebagai mitra Bumdes. Meskipun pada pelaksanaannya tenaga kerja yang terserap belum mendapatkan upah sesuai dengan pekerjaan yang mereka lakukan.

Hal ini dikarenakan profit yang diterima Bumdes baru mampu menutupi kebutuhan operasional Bumdes. Keuntungan yang telah didapatkan saat ini dialokasikan untuk pengembangan usaha. Selain penyerapan tenaga kerja, Bumdes diharapkan mampu memberikan profit dan benefit kepada anggota Bumdes khususnya dan masyarakat desa pada umumnya. Benefit yang telah diperoleh dari keberjalanan Bumdes setahun ini adalah kemudahan yang diperoleh warga masyarakat Sungai Langka dalam memenuhi kebutuhan air minum. 
Di Desa Sungai Langka terdapat gedung yang tidak terpakai. Dahulu gedung ini digunakan sebagai poliklinik desa, namun beberapa tahun terakhir gedung ini tidak dimanfaatkan. Pada saat pembentuk Bumdes, gedung ini digunakan sebagai sektertariat Bumdes dan tempat pengisian ulang air minum hingga saat ini. Gedung ini terletak di dusun empat Desa Sungai Langka dengan bangunan seluas 36 $\mathrm{m}^{2}$. Dalam hal ini Bumdes tidak perlu mengeluarkan biaya sewa bangunan karena gedung telah dihibahkan oleh pemerintah Desa Sungai Langka kepada Bumdes Ramaksa.

Selain itu, Bumdes Ramaksa juga mendorong masyarakat untuk berwirausaha dengan permodalan yang diberikan oleh Bumdes. Bumdes juga berperan dalam memasarkan hasil produksi dari lembaga keuangan mikro. Produk dari lembaga tersebut seperti keripik pisang, keripik nangka, keripik talas, olahan coklat, hasil kerajinan tangan, dan produk lainnya. Pemasaran produk ini tidak hanya di Desa Ramaksa saja, tetapi sudah dipasarkan ke luar desa bahkan hingga wilayah Kota Bandar Lampung. Media yang digunakan dalam memasarkan produk yaitu personal selling dan handphone. Hal ini menunjukkan pemasaran produk oleh Bumdes belum memanfaatkan teknologi informasi berupa internet.
Pada unit usaha penggemukan kambing berlokasi di dusun delapan Desa Sungai Langka. Modal awal yang diberikan oleh Bumdes digunakan untuk membangun kandang kambing seluas 48 $\mathrm{m}^{2}$ dengan kapasitas 40 ekor kambing. Kandang kambing dibangun pada bulan Februari tahun 2018 di atas lahan kosong yang dimiliki oleh salah satu warga yang memiliki luas sebesar $76 \mathrm{~m}^{2}$. Sedangkan sisa dari modal awal digunakan untuk membeli pakan fermentasi. Unit usaha ini belum menghasilkan keuntungan karena modal yang dibutuhkan belum cukup untuk produksi.

Selain ketiga usaha yang telah dijelaskan, Bumdes Ramaksa juga memiliki unit usaha minuman kesehatan izaura. Usaha minuman kesehatan ini dikelola oleh salah satu pengurus Bumdes. Modal awal dialokasikan untuk membeli produk dari agen, biaya promosi dan transportasi. Usaha yang berjalan pada bulan November 2017 ini berhenti melakukan penjualannya pada bulan Februari 2018 dikarenakan kurangnya minat masyarakat desa dengan produk yang ditawarkan serta manajemen yang buruk sehingga usaha minuman izaura tidak layak untuk dijalankan. 


\section{PERSEPSI STAKEHOLDER TERHADAP PENGEMBANGAN BADAN USAHA MILIK DESA (BUMDES) DI SUNGAI LANGKA, KECAMATAN GEDONG TATAAN KABUPATEN PESAWARAN \\ Tri Pujiana, Dwi Arianti, Abdul Mutolib}

\section{b. Aspek Ekologi}

Aspek ekologi dari Bumdes Ramaksa ini adalah penggunaan bahan baku yang tersedia dari alam. Bahan baku ini berasal dari sumber mata air desa untuk unit usaha air minum. Bahan baku ini berbeda dengan bahan baku yang biasanya digunakan untuk unit usaha isi ulang air minum yang pada umumnya menggunakan bahan baku yang diperoleh dari Perusahaan Daerah Air Minum (PDAM). Usaha isi ulang air minum ini tidak menghasilkan limbah industri sehingga secara aspek ekologis usaha ini tidak merugikan masyarakat desa.

Selain bahan baku berupa air yang berasal dari pegunungan, bahan baku yang digunakan untuk unit usaha Bumdes Ramaksa adalah buah-buahan yang diolah menjadi keripik. Bahan baku ini akan menghasilkan limbah pada proses pengolahannya. Namun oleh masyarakat desa limbah tersebut dijadikan sebagai bahan makanan ternak kambing. Kambing yang dipelihara oleh masyarakat desa juga merupakan kambing milik Bumdes. Limbah dari kambing yang dipelihara juga dimanfaatkan sebagai pupuk organik untuk tanaman perkebunan milik petani desa. Hal ini menunjukkan bahwa unit usaha yang dimiliki oleh Bumdes Ramaksa tidak memberikan dampak negatif bagi masyarakat Desa Sungai Langka itu sendiri.

\section{c. Aspek Sosial}

Aspek sosial dari pembentukan Bumdes Ramaksa berdasarkan persepsi stakeholder adalah adat dan kebudayaan. Informan beranggapan bahwa pengelolaan Bumdes harus seiring dengan adat dan kebudayaan masyarakat sekitar. Hal ini dianggap efektif untuk menghindari konflik dan penolakan oleh warga. Pemanfaatan bahan baku berupa air pegunungan merupakan contoh pengelolaan Bumdes berdasarkan kebudayaan masyarakat setempat yang memang mengonsumsi air dari mata air tersebut.

Aspek sosial juga dilihat dari partisipasi masyarakat dalam mendukung program Bumdes. Masyarakat merasakan dampak positif dengan berdirinya Bumdes tersebut. Bumdes memberikan kemudahan pada masyarakat dalam memenuhi kebutuhan air minum tanpa harus merebus terlebih dahulu. Masyarakat dapat menghemat keuangan rumah tangganya selain karena harga air minum isi ulang ini relatif murah. Partisipasi masyarakat dalam pengelolaan Bumdes juga terlihat dari peran aktif dalam setiap pertemuan dan rapat evaluasi tiga bulanan untuk pengurus Bumdes. Mereka juga ikut dilibatkan dalam proses pengambilan 
keputusan yang bersifat umum dan teknis di masing-masing unit usaha Bumdes Ramaksa.

\section{d. Aspek Kelembagaan}

Aspek kelembagaan yang menjadi perhatian dalam pengelolaan Bumdes Ramaksa menurut persepsi stakeholder adalah ketersediaan dana dan peraturan lembaga. Hal tersebut berdasarkan kondisi keuangan Bumdes belum mandiri dan belum mampu memberikan sumbangan pada pendapatan masyarakat dan desa. Ini disebabkan karena Bumdes baru berjalan selama satu tahun dan dalam proses pengembangan unit usaha yang ada di dalamnya. Untuk tetap bertahan dan terus berkembang, Bumdes memerlukan dana yang sangat besar di samping kesiapan institusi dan SDM-nya.

Persepsi tentang pentingnya peran Bumdes dalam mendukung pembangunan desa diwujudkan melalui berbagai peraturan yang memberikan kewenangan terhadap pengelolaan Bumdes. Informan berpendapat bahwa Bumdes akan bekerja dengan baik jika dilandasi dengan hukum dan peraturan yang jelas serta tegas. Payung hukum tentang pengelolaan Bumdes yang dituangkan dalam peraturan pemerintah daerah dalam mewujudkan Bumdes dan peran serta stakeholder dalam mendukung pengelolaannya.
Masing-masing unit usaha di Bumdes Ramaksa memiliki peraturan yang harus ditaati oleh seluruh pihak yang terlibat. Misalnya pada usaha lembaga keuangan mikro yang memiliki prosedur dalam proses peminjaman. Warga yang ingin meminjam uang harus membawa fotokopi KTP dan KK, menjelaskan uang yang dipinjam untuk usaha apa dan prospek ke depannya apakah menguntungkan atau tidak. Setelah itu, petugas akan melakukan survei ke tempat tinggal atau tempat usaha warga yang ingin meminjam modal. Apabila petugas telah sepakat untuk meminjamkan uang sebagai modal, maka warga yang ingin meminjam uang akan memilih jumlah pinjaman yang dibutuhkan. Dalam hal ini pengembalian pinjaman dapat dilakukan dalam waktu 1 bulan dengan bunga 5\%, 3 bulan dengan bunga $9 \%$, atau 6 bulan dengan bunga $11 \%$.

Menurut informan, pembentukan Bumdes Ramaksa sudah sesuai dengan undang-undang yang berlaku. Bumdes didirikan sesuai dengan kebutuhan dan potensi desa. Bumdes Ramaksa dibentuk sebagai badan usaha yang memenuhi kebutuha pokok masyarakat desa, memanfaatkan sumberdaya yang sebelumnya tidak dimanfaatkan secara optimal, dan memanfaatkan sumberdaya manusia untuk mengelola dan menggerakkan Bumdes sebagai 


\section{PERSEPSI STAKEHOLDER TERHADAP PENGEMBANGAN BADAN USAHA MILIK DESA (BUMDES) DI SUNGAI LANGKA, KECAMATAN GEDONG TATAAN KABUPATEN PESAWARAN \\ Tri Pujiana, Dwi Arianti, Abdul Mutolib}

aset perekonomian masyarakat serta Bumdes mengakomodasi dan mendorong unit-unit usaha yang dikelola untuk meningkatkan kesejahteraan masyarakat desa.

Keterlibatan pemerintah Desa Sungai Langka dalam pembentukan Bumdes Ramaksa yaitu sebagai penyerta modal terbesar dan sebagai pendiri bersama masyarakat. Pemerintah desa memberi proteksi (perlindungan) terhadap inventaris milik Bumdes. Pemerintah desa juga ikut berperan dalam pembentukan Bumdes sebagai badan hukum yang berlandaskan pada aturan perundangan yang berlaku, sesuai dengan kesepakatan yang terbangun di masyarakat desa.

Suatu usaha tidak mungkin tidak ada kendala dalam pelaksanaannya, begitu juga dengan unit usaha yang ada di Bumdes Ramaksa ini. Kendala yang sering timbul yaitu permasalahan dalam mendistribusikan produk isi ulang air minum pada saat hujan, adanya pesaing usaha sejenis dan ketergantungan pada listrik pemerintah yang apabila listrik mati maka proses produksi air minum tidak bisa berjalan. Selain itu galon milik Bumdes yang digunakan sebagai tempat air isi ulang tidak dibeli oleh konsumen melainkan dipinjamkan sehingga berdampak pada keterbatasan produksi isi ulang air minum padahal permintaan konsumen cukup banyak.
Pada unit usaha keuangan mikro, kendala yang dialami yaitu sulitnya peminjam modal untuk membayar angsuran yang telah disepakati diawal. Pengurus juga tidak mau memaksa peminjam untuk membayar angsuran tersebut. Hal ini kemudian diatasi dengan pemberian surat peringatan (SP) dalam tiga tahap. Tiga tahap tersebut, yaitu peringatan secara lisan, peringatan secara tertulis, dan terakhir pencabutan usaha milik peminjam modal. Namun, pada pelaksanaannya pun masih belum maksimal karena adanya rasa sungkan pengurus unit usaha kepada peminjam modal.

\section{KESIMPULAN DAN SARAN}

Unit usaha yang dijalankan oleh Bumdes Ramaksa antara lain unit usaha pengelolaan isi ulang air minum, lembaga keuangan mikro, peternakan, dan sub agen air minum Izaura. Pemilihan unit usaha ini didasarkan pada sumber daya dan potensi yang ada di Desa Sungai Langka. Bumdes Ramaksa dibentuk berdasarkan asas manfaat dan peningkatan kesejahteraan masyarakat desa. Persepsi stakeholder terhadap pengembangan Bumdes Ramaksa dilihat dari empat aspek, yaitu aspek ekonomi, ekologi, sosial dan kelembagaan. Dari keempat aspek yang dinilai, Bumdes Ramaksa sudah tergolong baik. Menurut informan, 
program Bumdes sebagai inplementasi program pemberdayaan masyarakat berupaya untuk menciptakan pertumbuhan di bidang ekonomi rakyat dan pemerataan kesejahteraan melalui perluasan kesempatan berusaha bagi usaha kecil masyarakat yang diukur dari peningkatan pendapatannya.

$$
\text { Perlu adanya peningkatan }
$$

manajemen pengelolaan Bumdes di tingkat pengurus agar kendala-kendala yang terjadi dapat diatasi. Selain itu, diperlukan seleksi terhadap unit-unit usaha yang tidak memberikan keuntungan baik profit maupun benefit kepada Bumdes Ramaksa. Perlu juga dilakukan pendekatan secara sosial budaya untuk meningkatkan partisipasi pengurus Bumdes dan masyarakat desa dalam peningkatan peran Bumdes.

\section{DAFTAR PUSTAKA}

Alfiya, et al. 2012. Persepsi Para Pemangku Kepentingan terhadap Pengelolaan Lanskap Hutan di Daerah Aliran Sungai Tulang Bawang. Jurnal Penelitian Sosial dan Ekonomi Kehutanan 9(4): 171184.

Amanda, H.W. 2015. Strategi Pembanguan Desa Dalam Meningkatkan Pendapatan Asli Desa Melalui Badan Usaha Milik Desa (Bumdes) Studi Pada Badan Pengelola Air Minum (BPAM) di Desa Ketapanrame Kecamatan Trawas Kabupaten Mojokerto. Jurnal Publika 3(5): VII-XII.
Atmojo, ST. 2015. Peran Badan Usaha Milik Desa (Bumdes) dalam Pemberdayaan Masyarakat Desa (Studi Kasus Pada Badan Usaha Milik Desa (Bumdes) Di Desa Temurejo Kecamatan Bangorejo Kabupaten Banyuwangi). Skripsi. Ilmu Kesejahteraan Sosial. Fakultas Ilmu Sosial dan Ilmu Politik. Universitas Jember.

Bangsawan, I. 2017. Analisis FaktorFaktor Perkembangan Desa dan Strategi Menuju Desa Mandiri (Studi Di Desa Sungai Langka Kecamatan Gedong Tataan Kabupaten Pesawaran). Skripsi. Fakultas Ilmu Sosial dan Ilmu Politik. Universitas Lampung.

Beding PA. 2015. Persepsi Petani terhadap Inovasi Teknologi Pengelolaan Tanaman Terpadu Padi Gogo di Kabupaten Sarmi Provinsi Papua. Jurnal Agritech 17(1): 65-72.

Chintary dan Lestari. 2016. Peran Pemerintah Desa dalam Mengelola Badan Usaha Milik Desa (Bumdes). Jurnal Ilmu Sosial dan Ilmu Politik 5(2): 59-63.

Januraga, et all. 2009. Persepsi Stakeholder terhadap Latar Belakang Subsidi Premi, Sistem Kapitasi dan Pembayaran Premi Program Jaminan Kesehatan Jembrana. Jurnal Manajemen Pelayanan Kesehatan, 12(1): 33-40.

Kurniawan, A. 2016. Peranan Badan Usaha Milik Desa (Bumdes) dalam Peningkatan Pendapatan Asli Desa (Desa Lanjut Kecamatan Singkep Pesisir Kabupaten Lingga Tahun 2015). Jurnal Ilmu Pemerintahan Fakultas Sosial dan Ilmu Politik.

Ridlwan, Z. 2014. Urgensi Badan Usaha Milik Desa (Bumdes) dalam pembangunan Perekonomian Desa. Jurnal Ilmu Hukum 8(3): 424-440.

Sugiyono, 2001. Metode Penelitian. CV. Alfa Beta. Bandung. 